\title{
Short-run Effects of Job Loss on Health Conditions, Health Insurance, and Health Care Utilization
}

\author{
Jessamyn Schaller* \\ Department of Economics, University of Arizona and NBER \\ 1130 E Helen St. Suite 401, Tucson, AZ, USA 85718 \\ jschaller@email.arizona.edu \\ Ann Huff Stevens \\ Department of Economics, University of California, Davis and NBER \\ 1 Shields Ave. Davis, CA 95616 \\ annstevens@ucdavis.edu
}

Job loss in the United States is associated with reductions in income and long-term increases in mortality rates. This paper examines the short-run changes in health, health care access, and health care utilization after job loss that lead to these long-term effects. Using a sample with more than 10,000 individual job losses and longitudinal data on a wide variety of health-related outcomes, we show that job loss results in worse self-reported health, activity limitations, and worse mental health, but is not associated with statistically significant increases in a variety of specific chronic conditions. Among the full sample of workers, we see reductions in insurance coverage, but little evidence of reductions in health care utilization after job loss. Among the subset of displaced workers with chronic conditions and those for whom the lost job was their primary source of insurance we do see reductions in doctor's visits and prescription drug usage.

We are grateful for comments from participants at the University of Arizona, the University of California Merced, the University of California Riverside, Pomona College, Georgia Institute of Technology, and the Annual Meetings of the Society of Labor Economists. Finally, support from the National Science Foundation, IBSS grant \# SMA1327768 is gratefully acknowledged.

*Corresponding author. 
Over the course of the Great Recession more than eight million Americans lost their jobs. A growing body of research in economics points to adverse and long-lasting consequences of worker displacement. These include significant decreases in lifetime earnings, reduced job stability, increased likelihood of divorce, lower fertility, and negative impacts on health, education, and labor market outcomes for the children of the displaced. ${ }^{1}$ A particularly grim addition to this literature is the finding that job loss results in sharply increased mortality for US workers. Sullivan and von Wachter (2009) estimate that displacement is associated with a 10$15 \%$ increase in a worker's annual death hazard - an implied loss in life expectancy of 1-1.5 years for an individual displaced at age 40 .

Despite the dramatic magnitude of the mortality effects of job loss in Sullivan and von Wachter's study, little is known about why job loss leads to increased mortality. Many potential pathways exist, including reduced income and access to health insurance, reductions in continuity of care due to changes in insurance coverage or geographic mobility, increased prices of health care as a result of insurance loss or changes, and the substantial stress associated with reduced and variable earnings following job displacement. Persuasively identifying how job loss leads to reduced health is made difficult by the fact that poor health may lead to selection for displacement, or to difficulty becoming re-employed, both of which can raise doubts about causality in cross-sectional comparisons, even with large sample sizes and many control variables. These factors make it critical to utilize methods - often based on longitudinal data - that can more clearly establish the direction of causality between job loss

\footnotetext{
${ }^{1}$ See, among others, Ruhm (1991), Jacobson, Lalonde and Sullivan (1993), Stevens (1997), Charles and Stephens (2004), Lindo (2009), Lindo (2011), Stevens and Schaller (2011), Oreopoulos, Page, and Stevens (2008).
} 
and health outcomes. The multiple potential pathways by which job loss may affect health also make it important to consider a variety of outcomes, including health conditions, utilization of medical care, and insurance coverage, in the same study and estimation framework.

This paper combines short panels from the Medical Expenditure Panel Survey (MEPS) covering the years 1996 through 2012 to study the effects of job loss on health conditions, health insurance coverage, and health care utilization and expenditures. The MEPS is uniquely suited for analysis of the health effects of displacement and allows us to improve on existing research in two ways. First, by combining many panels of the MEPS data we generate larger sample sizes of displaced workers than are typically available from non-administrative data, with over 10,000 involuntary job losses. This allows us to estimate models that more convincingly isolate the causal impact of job loss on health outcomes without concerns about statistical power. At the same time, because the MEPS contains detailed longitudinal information on a variety of health outcomes, health insurance coverage and its source, and detailed (self-) reports of expenditures on and utilization of health care, we are able to gain a broader understanding of the health effects of job loss and explore potential mechanisms behind our main effects.

Using models that include individual fixed effects and baseline health measures interacted with trends, we find that involuntary job loss is associated with a significant decline in self-reported mental health and increases in depression and anxiety. We also find that job loss results in a significant decline in self-reported physical health and increases in limitations on work and recreational activities. However, we find no significant effects of displacement on 
the incidence of diabetes, arthritis, hypertension, heart disease or high cholesterol within the first two years following job loss. Moreover, we find no evidence of increases in the incidence of trauma following displacement and we find that job loss results in significant reductions in the incidence of infectious disease. ${ }^{2}$

Turning to estimates of the effects of displacement on insurance status and health care utilization, we find that job loss is associated with a 17 percentage point increase in the probability of experiencing a spell without health insurance in the current interview round and a 13 percentage point decrease in the probability of being covered by any health insurance at the time of the next interview. The effects of job loss on health care utilization and expenditures are small for the sample as a whole, but we do find that job loss negatively impacts utilization among the sample of workers who held insurance through their employer prior to the job loss. Focusing on this group, we find no evidence that greater incidence of insurance loss leads to larger negative effects on health or mental health conditions in the short-run. When we limit our sample to people with existing chronic conditions prior to job loss, we find larger reductions in health care utilization, including prescription drug use, and larger increases in activity limitations and depression and anxiety following displacement. This suggests that some chronic conditions may become worse after displacement as people forgo medical care.

Overall, our results suggest that involuntary job loss has negative effects on the health of displaced workers in the short run, with significant effects on mental health, activity

\footnotetext{
${ }^{2}$ The reduction in infectious disease is consistent with the findings of Schaller and Zerpa (2014), who use MEPS data to look at the effects of parental job loss on child health and also find reductions in infectious disease among children following displacement.
} 
limitations, and self-reported health status. However, these effects are not accompanied by immediate increases in common chronic medical conditions or increases in traumatic injury or infectious illness. We also find that loss of insurance following displacement seems to drive reductions in health care utilization, but does not seem to result in more pronounced negative effects on self-reported health or mental health problems.

Our results are consistent with several possible mechanisms that could lead to longterm increases in mortality. First, we show reduced utilization of health care and prescription drugs, particularly among those losing insurance coverage. This could lead, ultimately, to increases in undiagnosed and untreated chronic diseases, such as hypertension or heart disease. Of course, it will remain difficult to show this directly given that this mechanism relies on undiagnosed conditions. Second, increased stress and anxiety following job loss, for which we find very strong evidence, may ultimately lead to deterioration in physical health. Finally, we show that those with chronic conditions do seem to reduce their use of medical care following job loss, and so it may not be the onset of new conditions, but rather, less careful management and treatment of them, that could lead to long-term mortality effects.

\section{Related Literature}

The background for this study and many other recent studies comes from early work that establishes the large and permanent effects of job loss on earnings (Jacobson, Lalonde, and Sullivan (1993), Couch and Placzek (2010)) and, more recently, the large effects of job loss on mortality. Specifically, Sullivan and von Wachter (2009) show that displaced workers are 10- 
$15 \%$ more likely to die in the two decades following job loss. ${ }^{3}$ These results are concentrated among workers losing jobs before age 50 , with older displaced workers facing much smaller mortality effects in the aftermath of job loss. Sullivan and von Wachter also show that the extent of the mortality effects seem to be correlated with the size of earnings losses and the volatility of earnings after job loss. Unfortunately, the administrative data utilized by Sullivan and von Wachter do not contain any information on the cause of death, or the types of underlying health changes that could lead to increased mortality.

These findings have sparked several recent investigations into short- and medium-run health changes that result from displacement. Findings using data from the United States (where evidence on negative earnings and mortality effects from job loss is strongest) produce mixed results. Salm (2009) uses the Health and Retirement Study (HRS) and a sample of workers ages 50 and over and finds little evidence of negative effects of job loss on mental or physical health outcomes. This lack of effect for older workers (average age in Salm's sample is 55 years) is consistent with the work by Sullivan and von Wachter (2009) who argue that older workers may be close enough to eligibility for retirement benefits that the earnings losses and uncertainty that follow displacement are mitigated and with them, many of the negative health effects. Salm also has a relatively small sample (around 370) of displaced workers (defined as those losing jobs due to firm closings) and includes only two observations per worker-one preand one post-displacement. Other work using the HRS (Gallo, et al. (2000), for example) faces similar sample size and age limitations.

\footnotetext{
${ }^{3}$ Smaller mortality effects have been found using European administrative data (Rege, Telle, and Votruba (2009), Eliason and Storrie (2009), Browning and Heinesen (2012)).
} 
Using data from the Panel Study of Income Dynamics, Strully (2009) finds that job loss is associated with a higher likelihood of self-reported fair or poor health and increased onset of new health conditions. Her sample includes a broader set of ages, but includes only 200 workers losing jobs due to a firm closing. She finds some evidence of negative effects on selfreported health and increases in the onset of new conditions after job loss. These results include controls for baseline health reports, but look only at a single point in time after the job loss.

Several studies have utilized large administrative data sets from European countries that contain large numbers of displaced workers, but typically lack repeated, longitudinal measures of health outcomes or other health measures. Black, Devereux, and Salvanes (2012), for example, have longitudinal data on earnings and employment for all of Norway, but observe health outcomes for individuals only at a single point in time. They use a rich set of individual characteristics to control for differences between displaced and not-displaced individuals, but are unable to control for individual fixed-effects in health measures or use longitudinal data on health. Black, Devereux, and Salvanes find that job loss results in small increases in smoking and reductions in an index of cardiac health. They also show, consistent with previous work on job loss in Norway, that the earnings effects of job loss are much smaller in Norway and that Norwegian workers have access to generous, long-term unemployment insurance. Thus it is unclear whether we would expect very large associated health effects in this setting. They do not have information on health insurance coverage or healthcare utilization. Other papers have also pointed to relatively modest health effects after job loss using European data (see Bergemann et al. (2011), Browning et al. (2006), Browning and Heinesen (2012)). 
The findings of relatively small health effects in Europe could reflect that job loss may be less of an economic shock in Europe than in the United States, given more generous social insurance and employment stability policies. It could also reflect broader availability of health insurance not tied to employment. Overall, the limitations of existing studies leave open the question of how, in the United States at least, the economic shock associated with job loss is translated into increased mortality.

Another limitation of the existing literature is that alternative health-related outcomes have been analyzed in isolation. The above studies focus on health conditions or self-reported health, while separate studies have looked at effects on insurance coverage (Gruber and Madrian (1997), Lin (2005)). Job loss generates reductions in insurance coverage, and may change access and costs of care for many, and these could be related to short- and long-term changes in health. Only by analyzing health conditions, insurance, and health care utilization in a unified study are we likely to make progress on understanding the full health effects of job loss.

Given this backdrop, our paper makes an important contribution by combining U.S. data on job losses, which we know are associated with both large earnings losses and large mortality effects, with a variety of health-related outcome measures for individuals in their prime working years. In addition, because we have longitudinal data and repeated observations (up to five observations per worker) of our health measures, we can use more robust models to control for unobserved characteristics that may be correlated with job loss. Specifically we include individual fixed-effects and baseline health and mental health measures interacted with 
trends to isolate the effects of job loss on several key health outcomes. We can also compare results across displaced workers with different baseline insurance sources and status, to gain clues about the likely drivers of the health effects of job loss. In a supplemental analysis, we confirm our main findings on the relationship between job loss and physical health using data on older workers from the Health and Retirement Survey.

\section{Statistical models of the health effects of job loss}

Our approach to understanding the health effects of job loss is motivated by the wellestablished empirical models of job loss and earnings, but also informed by a standard health production function. Many previous authors (Jacobson, Lalonde, Sullivan 2003, Stevens 1997, Schmieder, von Wachter and Bender, 2012) model earnings effects of job loss using specifications such as:

$$
\begin{aligned}
& \ln E_{i t}=\alpha_{i}+\gamma^{k} \sum_{i=-2}^{i k} D_{i i}^{k}+\beta X_{i t}+Y_{1}+\varepsilon_{i !} \\
& \ln E_{i i}=\alpha_{i}+\delta_{i} t+\gamma^{k} \sum_{i=-2}^{k} D_{i t}^{k}+\beta X_{i i}+Y_{1}+\varepsilon_{i t}
\end{aligned}
$$

The log of earnings $\left(E_{i t}\right)$ for person $\mathrm{i}$ in year $\mathrm{t}$ is modeled as a function of individual fixed-effects $\left(\alpha_{i}\right)$ and a vector of dummy variables indicating years before and after the job loss $\left(D^{k}{ }_{i t}\right)$. In some specifications, an individual-specific trend is also included, as shown in equation (1b). Additional control variables $\left(X_{i t}\right)$ may be included, such as higher order terms in age or experience, along with a set of calendar year dummies $\left(Y_{t}\right)$. The individual fixed effects and trends are necessary to isolate the effects of displacement from pre-existing levels or trends in earnings that may be 
correlated with job loss. Such specifications use observed earnings prior to job loss to establish the counterfactual pattern of earnings if the job loss had not occurred. A control group of never-displaced workers helps to estimate the common (to displaced and non-displaced workers) age and calendar year terms and identify the counterfactual pattern of earnings.

Using this framework to estimate the effects of job loss on health requires consideration of a simple health production function, as originally suggested by Grossman (1972). Specifically, let an individual's health stock in some period be expressed as a function of their lagged health, investment in health this period (I), and depreciation (at rate $\theta$ ) of health this period.

$$
H_{i !}=\left(1-\theta_{i t}\right) H_{i, i-1}+I_{i i}
$$

$$
I=F(M, T, \mathrm{E})
$$

Investment in health is in itself a function of market-based health care inputs (M), an individual's time devoted to improving health (T), and an individual's human capital $(E)$, which may affect the efficiency with which purchases of medical care or time investments produce next period's stock of good health.

Considering these inputs into health production jointly with the direct effects of job loss on employment, earnings, and health insurance coverage, it is easy to see how job loss can alter health. Earnings losses and employment changes may reduce spending on health care inputs (M). Loss of insurance may increase the price of health care inputs and so further reduce the quantity of health inputs. Time allocation towards health (T) may change after displacement, although the direction of this change is not clear. Less time may be spent in 
market work initially, but job changes, stress and uncertainty may result in less time being allocated toward health after displacement. Combining these factors and replacing earnings with health on the left-hand-side of equation (1a) or (1b), a dummy variable indicating displacement is likely to be associated with reduced health as the result of displacement's effects on health expenditures and (possibly) time investments.

An important element of previous studies of displacement that we extend to our estimates of the health production function is the use of a fixed-effects specification, or similar methods, to control for unobservable individual characteristics. A primary concern in this case is that human capital $(E)$, which is a key determinant of health in our production function, is likely to have both observed and unobserved components that are correlated with job loss probabilities. Thus, in order to control for individual characteristics that might be correlated with earnings, human capital, and ability, it is important to include individual fixed effects, or otherwise utilize pre-displacement values of health outcomes. Given this, our main specifications are given by:

(4a) $\quad H_{i !}=\alpha_{i}+\gamma \beta D_{i !}+\beta X_{i i}+\gamma_{\mathrm{t}}+\varepsilon_{\mathrm{it}}$

(4b) $\quad H_{i !}=\alpha_{i}+\delta_{i} t+\gamma^{p} D_{i t}+\beta X_{i t}+\gamma_{\mathrm{t}}+\varepsilon_{i t}$

(4c) $\quad H_{i !}=\alpha_{i}+\theta H_{i j} t+\varphi M_{i t} t+\gamma \beta D_{i t}+\beta X_{i t}+Y_{t}+\varepsilon_{i t}$

Equation (4a) is a standard fixed-effects specification. Note that in some specifications (such as those in Tables 2 and 7) we include a single indicator for the post-displacement periods $\left(P D_{i t}\right)$, while in other specifications we explore dynamic effects by including separate dummies for one 
period prior to displacement, the round of displacement, and one or more periods after displacement. Equation (4b) adds the individual-specific trend, allowing for the possibility that underlying health may have a trend that is correlated with displacement. In practice, with a relatively small number of time periods per person, we may not have sufficient power in the longitudinal data to identify the person-specific trend. As an alternative, we estimate models in which we replace the individual time trend, $\delta_{i} t$, with interactions between baseline (round 1 ) self-reported health and mental health and a time trend. In this specification, summarized by (4c), the effects of job displacement will be identified by deviations from these health trends. ${ }^{4}$

The inclusion of individual-specific trends, or baseline health interacted with trends, requires caution. In particular, including these trends can potentially lead to misspecification if there are dynamic responses to displacement that are not included in the model. An important example of this problem, and clear discussion of the issue can be found in Wolfers (2003). Recognizing this, we allow for dynamic treatment effects in many of our results to avoid such misspecification issues.

We will later argue that the specification with some form of interacted trends is our preferred approach, and we provide further evidence to support that choice in the results section. For now, however, we note two key points that guide our choice to focus on specification 4c. First, health measures at baseline are clearly correlated with the likelihood of

\footnotetext{
${ }^{4}$ We have also estimated a set of alternative trend specifications. First, we included a trend interacted with dummies for each integer value of self-reported health and mental health and obtained nearly identical results. Second, we replaced the health trends with trends defined instead by demographic characteristics (race, gender, and educational attainment), which also generated similar results. Finally, we estimated the full model described in (4b) allowing individual-specific trends, rather than a trend interacted with baseline health values; estimates are less precise but results are again similar.
} 
displacement; this becomes clear when we present sample means by displacement status in Table 1. This, of course, makes it critical to rely on individual-specific fixed effects or include other baseline controls. Second, with respect to trends, it is also clear from simple data tabulations that there are differential trends by baseline health status even among nondisplaced workers. If trends are correlated with baseline health, which is itself correlated with the likelihood of displacement, it is essential to rely on the trends specifications to avoid omitted variables bias.

\section{Data}

The data for this analysis are from the Household Component of the Medical Expenditure Panel Survey (MEPS), maintained by the Agency for Healthcare Research and Quality. The MEPS collects data from a nationally representative subsample of households that participated in the prior year's National Health Interview Survey (conducted by the National Center for Health Statistics). The MEPS interviews respondents five times over a period covering two calendar years, collecting data on demographic characteristics, health status, health care utilization and expenditures, health insurance coverage, income, and employment status. Our data include sixteen waves of the MEPS, covering the period 1996-2012. We limit our analysis to individuals between the ages of 21 and 65 that are employed in the first round of the survey. ${ }^{5}$

\footnotetext{
${ }^{5}$ Additional analysis, available upon request, shows that our results are very similar if we instead restrict the sample to include only individuals that worked full time in the first round of the survey, or to individuals with one or more years of job tenure in round 1 .
} 
The MEPS is ideally suited to this analysis for a few reasons. First, the set of health outcomes identified in the MEPS is far broader than those used in previous studies, allowing us to study not only general self-reported health and mental health, but also a variety of specific conditions including mental health conditions, chronic conditions such as diabetes and heart disease, trauma, and infectious illness. Second, the MEPS allows us to go beyond the health consequences of displacement and study the potential mechanisms behind this relationship changes in insurance coverage, the frequency of medical care, and total expenditures on care. Finally, we are not limited by small sample sizes, as previous panel data studies have been. By combining MEPS data from 1996 through 2012 we almost 500,000 person-round observations and observe over 10,000 job losses.

Our indicator for job displacement is constructed from a survey question asking the respondent to identify the main reason why he or she changed jobs since the last round of interviews. We define involuntary job loss to include three responses: (1) job ended; (2) business dissolved or sold; and (3) laid off. By this definition, we identify 10,631 individuals that experience involuntary job displacement after round 1 of the survey, and 97,885 individuals that are never displaced.

Our outcome variables fall into three categories: (1) health outcomes; (2) health insurance status; and (3) health care utilization. Data on health outcomes are compiled from the main MEPS household survey file and the Medical Conditions file. In the household survey, the respondent was asked to rate the health and mental health status of each person in the family according to the following categories: excellent, very good, good, fair, and poor. From 
these variables, we create indicators equal to one if health and mental health were recorded to be fair or poor. We also consider variables indicating whether the respondent reported any limitations on work, housework, or schoolwork or on social or recreational activities. The Medical Conditions file includes specific health conditions that were reported directly from the respondent, recorded verbatim by the interviewer, and then coded by professional coders to ICD-9-CM codes. Medical conditions can appear in a given round in one of several ways. First, conditions categorized as "priority conditions" are asked about in a condition enumeration section of the main survey and coded as present for a specific round if they are described as "current" in the survey for that round. Second, health conditions associated with specific events occurring in each round, such as hospital stays, doctor visits, disability days, and prescription drug purchases, are added to the file. Finally, respondents may report that a specific condition is "bothering" them during a survey round. To preserve confidentiality, condition codes are collapsed to 3-digit code categories. We use these 3-digit codes to identify a set of nine specific conditions: arthritis, diabetes, high cholesterol, hypertension, heart disease, trauma, infectious illness, and cancer (potentially a placebo test for direct health effects of displacement), and anxiety or depression. ${ }^{6}$

Health insurance indicators are constructed from variables identifying whether a survey respondent was covered by a particular type of insurance at any time during each month of the

\footnotetext{
${ }^{6}$ As most of the conditions that we consider are considered "priority" conditions (with the exception of trauma and infectious illness), the reporting of the conditions should not be mechanically dependent on the utilization of care (i.e. the number of health "events" in a specific round). However, to the extent that individuals are more likely to describe as "current" a condition for which they have recently seen the doctor or filled a prescription, utilization of medical care and likelihood of reporting medical conditions may be correlated. It is also possible that frequent care makes it more likely that individuals will be diagnosed and thus become aware that they have a specific medical condition.
} 
panel. The variables are equal to one if the respondent was insured at any point during the month of the interview. In order to capture spells without insurance, we also generate a variable equal to one if the respondent was without insurance for any month of the round.

Finally, data on health expenditures and health care utilization come from three separate event file components of the MEPS - the Prescribed Medicines file, the Emergency Room Visits file, and the Office-Based Medical Providers file. These files contain data on the number of office-based visits to a doctor and number of visits to the emergency room, as well as the amount paid by family, insurance, and other sources for each medical event that occurred in the round, including the purchase of prescription drugs. We collapse the data to the person-round level to generate total number of visits and expenditures by category for each individual.

\section{RESULTS}

\section{a. Summary Statistics}

Sample means, presented in Table 1, make clear the importance of controlling for observable and unobservable characteristics that may be correlated both with the likelihood of involuntary job displacement and with health-related outcomes. We compare characteristics for two groups: workers who experience an involuntary displacement sometime after the first round of data collection and workers who are never displaced. ${ }^{7}$ Displaced workers are more

\footnotetext{
${ }^{7}$ Observation numbers in Table 1 show that there is sample attrition between rounds 1 and 5 . If workers who experience negative health shocks after displacement are more likely to leave the sample, this could bias our estimates toward zero. To place bounds on our estimated effects, we estimated models in which we replaced all
} 
likely to be male, more likely to be black or Hispanic, and slightly younger than their continuallyemployed counterparts. They are also less-educated: 15.7 percent of the displaced sample has less than a high school degree, compared with 9.7 percent of the non-displaced group, and 48 percent have attended any college, compared with 55.8 percent of the non-displaced group.

Differences between the displaced and non-displaced groups are also apparent when considering health-related outcomes. Notably, while displaced workers are more likely to have their general health categorized as fair or poor and are more likely to experience poor mental health, they are less likely to report high cholesterol, heart disease, hypertension, or cancer. While this discrepancy may be due to differences in the prevalence of these conditions between these two groups, it also may be due to the reduced rate of health insurance coverage among workers that will eventually be displaced: only 68.7 percent of the displaced sample is covered by any insurance in the initial round of the sample, while 84.1 percent of the neverdisplaced sample is covered. The gap in health insurance coverage may also explain differences in health care utilization between the two groups even prior to any displacements: displaced workers are less likely to visit the doctor's office, and less likely to use prescription drugs, and more likely to visit the emergency room, where treatment can often be obtained without health insurance.

The summary statistics in Table 1 suggest that it may be critical to check sensitivity of these results to adjusting for pre-existing differences in insurance coverage between displaced

missing health variables with the worst possible outcomes and models in which we replace all missing health variables with the best possible outcomes. These estimates are very similar to our main estimates, which suggests that nonrandom attrition is not driving our results. We have also conducted analysis on a balanced panel -a sample in which every observation has complete data in each round of the panel - and find that our results are robust to this sample change. 
and not displaced workers. If less financially stable firms, for example, are less likely to offer health insurance policies for their workers, there could be substantial selection of workers into firms that are most likely to close or lay off their workers, leading to bias in estimates of the effects of job loss that cannot control for insurance status. This could mean that those who are displaced would have been less healthy even in the absence of the job loss, given their lower levels of access to health coverage. In contrast, if healthier workers disproportionately select into firms that do not offer health insurance as part of their compensation package, the resulting bias could go in the other direction. Our inclusion of both fixed-effects and trends interacted with baseline health, which has not often been done in previous work, reduces the likelihood that results are driven by pre-displacement differences across workers. We also conduct some of our analysis on the subset of workers who have insurance through their employers as of round 1, and prior to any of the displacements. This results in a better balance of displaced and non-displaced workers and allows us to draw some suggestive conclusions about the role of insurance in driving effects on health outcomes and utilization for this subset of workers.

\section{b. Effects of Job Loss on Health and Mental Health Outcomes}

Table 2 shows results from a baseline set of health regressions in which we compare results across three different regression specifications. We define displacement broadly to include those who report that they were laid off, their job ended, or their business was dissolved or closed (in a robustness check we will later interact displacement effects with the 
reason for displacement to isolate the effects of business closures). In order to compare alternative regression specifications, these models include a single indicator for displacement prior to the current interview. To account for both observable and unobservable differences between displaced and non-displaced workers, our starting point is a standard specification, described in equation (4a) above that includes individual fixed effects; these results are summarized in column (3) of Table 2. For comparison, column (1) of that table shows mean levels of each health outcome as of round 1 and column (2) shows a specification without individual fixed-effects that instead includes controls for baseline self-reported health and mental health and dummies for gender, race, and educational attainment categories in addition to age and calendar year fixed effects - an approach that has been common in the previous literature. Finally, in column (4) we show our preferred specification (based on equation (4c)) that includes both individual fixed-effects and an interaction between round 1 self-reported health and a trend, meant to proxy for individual-specific trends that are correlated with underlying health status.

We begin by looking at the effects of job displacement on general health outcomes, including self-reported health ranking and the presence of any limitations on work and recreational activities. The results in column 4 of Table 2 show that displacement increases the probability of having a self-reported physical health status of fair or poor by 1.37 percentage points, or roughly 16 percent of the baseline probability, with the effect statistically different than zero at the 1 percent level. The next rows of Table 2 show the effects of displacement on activity limitations. We find that job loss increases the likelihood of having a limitation on work- 
related activities and recreational activities by .57 percentage points ( 25.9 percent) and .48 percentage points ( 28 percent) respectively.

In the second panel of Table 2, we consider a variety of specific health conditions. Some of these conditions, such as heart disease, arthritis, and diabetes have been linked directly in the medical literature to stress (Cohen et al. (2007), Hasset and Clauw (2010), deBrouwer et al. (2010), Surweit, Schneider and Feinglos (1991)). Other conditions, such as high cholesterol and hypertension have not been linked directly to stress, but may reflect changes in health behaviors after displacement. Specifically, if job loss and the associated stress leads to changes in smoking, drinking, nutrition, or exercise, conditions likely to be affected by such behaviors may be affected as well, and we include cholesterol and hypertension to check for this mechanism. We also consider the incidence of trauma, the incidence of which is likely to be affected by changes in time use (for example, time spent driving, participating in manual labor, or exercising), and infectious disease, which is likely to reflect different levels of exposure to illness (for example, through employment, through visits to doctors' offices or hospitals, or through children's daycare attendance) after displacement and immune-system responses to stress. Finally, as a placebo test for direct health effects of displacement, we include cancer since it seems unlikely that any behavioral change (or changes to health care) from job loss would be associated with cancer diagnosis in the short time frame after job loss considered here.

As shown in the next two rows of Table 2, we find positive and significant increases in the incidence of arthritis and diabetes following job displacement with the fixed effects 
specification, but these effects are not robust to inclusion of baseline health interacted with a trend. We find no evidence of increases in high cholesterol, heart disease or hypertension. We do not see significant effects of job displacement on trauma in column 4, though we do see some evidence of a negative relationship when trends are not included, and we find that job loss is associated with a 7.5 percent reduction in infectious disease. Finally, as expected, we also find no increase in the onset of cancer, which suggests that we are not picking up spurious negative changes in health that are simply correlated with the likelihood of job loss.

Many previous papers have used some version of baseline health controls rather than an individual fixed-effects approach, and this may explain some of the differences between the results in Table 2 and some prior findings. Given the evidence in Table 1 that the displaced and non-displaced differ substantially on many dimensions even prior to the job loss, the more conservative approaches using individual fixed-effects and trends are our preferred estimate.

There are two main reasons that we focus on the specifications including trends interacted with baseline health in the remainder of the paper. First, there is strong evidence that, aside from any potential effects of displacement, individuals with different baseline health (which is itself associated with differential chances of displacement) also have differential trends in a variety of specific health outcomes. To explore this, we examined the trends in several different health outcomes for non-displaced individuals with different levels of baseline mental and physical health. We focused on the never-displaced group for this exercise to eliminate any chance of confounding effects of displacement over time with pre-existing trends. Results (not shown, but available upon request) indicate that there are substantial 
differences in trends in the onset of several chronic conditions across individuals with different values of self-reported baseline health. For example, among individuals who report being in good or excellent health as of wave 1, there is a fairly modest increase between waves 1 and 5 in the likelihood of reporting diabetes, of approximately 9 percent. In contrast, those who start the survey period reporting fair or poor health show an increase over time of more than 80 percent in the likelihood of diabetes onset. Given co-morbidities among many chronic diseases, it is not surprising to see this correlation between initial health status and trends in other health conditions. This also emphasizes that conditioning (via inclusion of individual fixed effects) on the baseline value of a particular health outcomes may not fully capture unobserved health status that is potentially correlated with displacement.

Second, there is a mechanical issue of top-coding in some of our outcomes. Specifically, consider individuals who report being in poor or fair health at the beginning of the sample. The trend in self-reported health for such individuals must be toward better health (a negative trend in our parameterization) since it cannot get any worse than "poor." Controlling for differential trends by initial health status avoids the possibility of an omitted variable bias from having a negative correlation between starting levels of health and the trend in health, along with the correlation between poor health and displacement.

Finally, before continuing with discussion of our additional results, we note that the fixed-effects approach slightly changes the interpretation of the results for individual conditions. For example, the point estimates in Table 2 for arthritis and diabetes are substantially larger prior to inclusion of fixed effects. Such specifications without fixed effects, 
however, may be driven by individuals who had these conditions even prior to job loss. In the fixed-effects specification, identification comes explicitly from individuals who go from not having the condition prior to job loss to reporting the condition following job loss. Thus, our results suggest little evidence that job loss leads to new onset of chronic conditions over the next two years. This also means that our fixed-effects (with or without trends) specifications for specific conditions are mainly identified from relatively healthy individuals who are at risk of developing the condition in later years. Below, we show additional results (for outcomes other than these specific conditions) that focus on the subset of individuals with some chronic condition at the beginning of the sample. In this way, we can see whether individuals who begin the period with worse health status have systematically different responses to displacement.

Returning to our results in the bottom panel of Table 2, we show effects of displacement on two mental health outcomes: a self-reported measure of mental health that is fair or poor, and a report of experiencing depression or anxiety. Mental health effects of displacement may play an important role in mediating the effects of job loss on physical health (see Cohen et al. (2007)) and also on a number of other outcomes that have been examined in the literature including marital dissolution and children's wellbeing. Not surprisingly, we find that job loss leads to substantial increases in both of these measures of mental health. The probability of self-reporting fair or poor mental health rises by a full 40.9 percent after job loss, and reports of depression or anxiety rise by 22.5 percent. 
In Table 3, we take our preferred specification from Table 2 (column 4) and replace the single post-displacement indicator with a set of indicators representing the round prior to displacement, the round of displacement (in other words, the interview immediately following displacement), and one or more rounds after displacement. This allows us to determine whether the health effects of job loss show up before the displacement happens (which may suggest potential endogeneity) and also to distinguish the immediate effects of displacement from those that occur in the next few months

The results in Table 3 show little evidence of changes in health that begin prior to displacement. The effects of job loss on self-reported health and mental health, as well as those on infectious illness don't show up until the interview immediately following displacement, and the effects on activity limitations are not significant until one or more periods after displacement. Effects on being in poor health and on reported anxiety or depression grow very slightly from the period of displacement to later rounds, but are generally similar across the two "post-displacement" periods.

\section{c. Effect of Job Loss on Health Insurance and Health Care Utilization}

The fact that we find significant increases in the number of workers reporting poor or fair health and activity limitations, but no increase in specific physical conditions is somewhat surprising. Of course, the increase in anxiety and depression could lead workers to report worse health. It may also be that other conditions and minor illnesses are occurring that lead to these reports, or that the changes reflect the worsening of existing medical conditions (we examine 
effects for individuals with existing chronic conditions below). However, reporting a specific condition requires that an individual has been diagnosed, or at least that they have selfdiagnosed, and this may depend on access to and utilization of health care, which we explore next. Previous work shows that individuals frequently mis-report specific conditions (see Baker et al. (2002)), and so self-reported summaries of health may be more reliable. It is also true that summary measures of self-reported health have been linked to mortality (Idler and Benyamini (1997)), and so may be particularly important here, given our interest in understanding the connections between short-term health effects of displacement and mortality.

We consider the extent to which displacement alters access to health insurance and health care utilization in Table 4. In Panel A we show the effects of displacement on several measures of insurance coverage, including the probability of having any insurance at the roundspecific survey date, the probability of having private or public insurance, and the probability of having any period (between interviews) uninsured. We see small reductions (of around 2 percentage points) in insurance coverage in the round just prior to job loss, ${ }^{8}$ but much larger effects at the time of job loss and after. Focusing on the indicator for any insurance coverage, for example, coverage falls by 13 percentage points in the round of the job loss, but recovers slightly to a 9.6 percentage-point reduction in later rounds. This effect consists of a slightly larger reduction in access to private insurance (which shows a reduction of approximately 14 percentage points immediately following displacement) and a small but statistically significant increase in access to public insurance. Finally, roughly 17 percent of those displaced experience

\footnotetext{
${ }^{8}$ This finding is not surprising in light of the literature on earnings losses from displacement, which shows that some of the effects appear prior to the displacement event, as firms begin to struggle and may reduce pay and hours (see, e.g. Jacobson et al. 1993).
} 
some period without insurance in the period of displacement and about 12 percent experience a spell without insurance in later rounds.

These effects are consistent with, though somewhat smaller than, previous estimates by Gruber and Madrian (1997) on the effects of job loss on insurance status. Gruber and Madrian report a reduction in the likelihood of having insurance after a job separation of approximately 20 percentage points. The fact that they include only men and consider both voluntary and involuntary changes job changes in their study may explain much of this difference. Importantly, the much larger effects at and following job loss provide additional evidence that these are direct effects of job loss, and not pre-existing characteristics of those workers who are most likely to lose jobs.

Panel B of Table 4 examines changes in health care utilization following job loss. Specifically, the outcomes we consider include having any office-based medical visits since the last survey round, any emergency room visits, or receiving any prescription medications, along with total expenditures on office visits, emergency room visits and prescription drugs. Interestingly, for these measures, there are some small but statistically significant increases in utilization (any office visit, any prescription drug coverage) in the round of the job loss. ${ }^{9}$ The effects become negative, as expected, in the period after displacement, though they remain relatively small. Once again, it is reassuring to see no evidence of effects emerging in the period prior to the displacement.

\footnotetext{
${ }^{9}$ While one natural interpretation of this pattern is that these increases reflect more utilization among those who anticipate losing coverage upon displacement, the results in section $\mathrm{Vb}$ (below) suggest that these effects must be related to declining health or mental health during this period, as we do not see this pattern for individuals who were insured through their employer in round 1.
} 


\section{EXTENSIONS AND ALTERNATIVE SPECIFICATIONS}

The results in the previous section show that involuntary job displacement, defined as job loss due to job ending, plant closure, or layoff, leads to worse self-reported general health and deterioration of mental health. However, we find little evidence of effects on the incidence of specific health conditions in our full sample. In this section, we extend our analysis in several ways. First, we investigate the extent to which changes in health insurance coverage and utilization drive changes in health following displacement by limiting our estimation sample to include only workers who held employer-sponsored health insurance prior to displacement. Second, we explore whether job loss as particularly detrimental health effects for individuals with chronic conditions prior to displacement. Third, we replicate our analysis using data on older workers from the Health and Retirement Survey-a dataset that has been used in several previous studies of the health effects of job loss. Finally, we check the robustness of our results to the use of an alternative definition of displacement that identifies only job losses due to plant closure.

\section{a. Round 1 Insurance Holders}

First, we consider a subset of workers who are likely to face larger changes in insurance coverage, and examine whether this group also has larger effects on health outcomes or utilization. Specifically, we limit our analysis sample to the group of individuals who, as of round 1 , are holding health insurance through their own employer ("round 1 insurance holders"). If the loss of insurance coverage drives other outcomes, such as health conditions or utilization, we would expect results for this subsample to differ from those in Tables 3 and 4 . This 
restriction eliminates from both our treatment and control groups those who are uninsured at round 1, as well as those who are insured, but whose coverage is through either a spouse's employer or an individual policy. A potential advantage of this approach is that it forces both treatment and control groups to be more similar in terms of observables (such as insurance status) at round 1 . While fixed-effects and baseline health trends are meant to correct for potential baseline differences between treatments and controls, this sample restriction may make the sample more similar in unobservable ways as well. Of course, the disadvantage is that the effects of displacement here apply to only a subset of job losers, and that subset, given their access to employer-based insurance in round 1 , may be relatively advantaged. ${ }^{10}$

Table 5 shows the effects of displacement in the sample that conditions on having ownemployer-based insurance in round 1 . As expected, the effects on access to health insurance are much larger and more persistent in this sample, with a 30.5 percentage point reduction in the likelihood of having any insurance immediately following job loss and a 27.2 percentage point reduction in insurance coverage in subsequent rounds. Echoing results in Table 4, the reduction in private insurance coverage from job loss is offset only very slightly by increased access to public insurance. There is only a 2.1 percentage point increase in the probability of having public insurance as the result of displacement one or more rounds later. This likely reflects limited eligibility for public insurance (Medicaid) for most able-bodied adults under current law, something that could change substantially as the Affordable Care Act is implemented in the coming years.

\footnotetext{
${ }^{10}$ Summary statistics for this and other subgroups of displaced workers are presented in Appendix Table A2.
} 
Consistent with the much larger reductions in insurance coverage for this subset of the sample, Panel B of Table 5 shows larger reductions in health care utilization. In particular, we find a 6.6 percentage point reduction in the likelihood of visiting the doctor, a 4.2 percentage point reduction in the likelihood of any prescription drug purchase, and a 62 dollar per round decrease in average expenditures on prescription drugs. Notably, these effects do not show up until at least one round after displacement, which suggests that the round-of-displacement increases in utilization seen for the full sample in the previous table were not driven by anticipation of insurance loss, but rather by contemporaneous changes in health in the period of displacement.

Taken together, the larger effects on insurance coverage for this sub-sample, along with larger reductions in health care utilization provide a rough guide to how disruptions in insurance status from displacement might affect the probability of receiving medical care. Suppose that all of the effect of displacement on health care utilization in this sample comes as the result of reductions in insurance coverage. In particular, this assumes (contrary to our findings) that there is no direct effect of job loss on health. Then, the results in Panels $A \& B$ of Table 5 suggest that loss of insurance coverage reduces office visits by approximately 24 percentage points and the use of prescription drugs by approximately 15 percentage points per round. These magnitudes are larger than the estimates in Currie and Gruber (1996), for children, that suggest becoming Medicaid eligible increased the probability of an office visit by approximately 9 percentage points per year. Of course, if displacement also produces independent, negative effects on health (perhaps due to stress or lifestyle changes), that would 
tend to increase the likelihood of medical visits and so this estimate may be a lower bound of the direct reduction in utilization from loss of insurance.

In the final panel of Table 5 we show the effects of displacement on health conditions for the sub-sample of round 1 employer-based insurance holders. This sample shows slightly smaller increases in the probability of reporting fair or poor health or activity limitations than the full sample, similar effects on fair or poor mental health, anxiety and depression, and slightly larger reductions in infectious disease. As in the full sample, there is no evidence of significant changes in the incidence of the specific chronic physical conditions. This suggests that, at least in the short-run, it is not access to insurance and health care utilization that drives negative effects on reported health and mental health immediately after job loss. It may be that reduced utilization, or reductions in continuity of care over a longer period, contribute to long-term effects on mortality, but we do not see evidence of specific physical conditions emerging in the years immediately after job loss.

\section{b. Individuals with Chronic Conditions}

One group of workers that is of particular interest to health policy makers is workers who have chronic health conditions prior to displacement. In particular, spells without insurance following job loss might cause disruptions in needed and time-sensitive care for these workers, resulting in especially severe health consequences. Studying this group of workers can also provide insight into whether the general health effects of job displacement seen in previous results are related to the worsening of existing conditions (which cannot be identified in our fixed effects specification). 
As shown in Appendix Table A2, displaced workers with chronic conditions have higher baseline health insurance coverage and high utilization relative to the full sample of displaced workers. Notably, they were 59 percent more likely to have visited a doctor's office, and 82 percent more likely to have purchased prescription drugs in round 1 of the survey than the full sample of displaced workers. Expenditures on doctor visits and prescription drugs were also more than twice as high for this group as for the full sample. Not surprisingly, workers with chronic conditions also report worse general health and mental health and more activity limitations prior to displacement.

We investigate the health effects of job loss for workers with chronic conditions prior to displacement in Table 6. The sample includes workers who report arthritis, diabetes, high cholesterol, heart disease, hypertension, or cancer in the first round. Despite having higher rates of baseline insurance coverage than the full sample of displaced workers, individuals with chronic conditions are not more likely to lose their insurance following job loss. Though this appears to contradict the results from Table 4, it is perhaps not surprising since people with chronic conditions are likely to seek insurance immediately from alternative sources such as a spouse's employer in order to maintain their level of care. Though the insurance effects are similar, the estimates in Table 6 suggest that workers with chronic conditions are giving up more when they lose their insurance, as they have large reductions in doctor visits and prescription drug utilization and expenditures. Job loss also appears to have more severe health consequences for these workers; they experience larger increases in the work and activity limitations and larger increases in the incidence of depression and anxiety. 


\section{c. Health and Retirement Survey}

To confirm our findings on the relationship between job loss and health conditions, we next perform a supplemental analysis using data from the Health and Retirement Study (HRS) from 1996 through 2010. We note that the HRS is not ideal for this study given the older age range of that sample and our interest in speaking to the phenomenon of long-term mortality effects of job loss. As discussed above, Sullivan and von Wachter (2009) find much smaller effects on mortality for those over age 50 at the time of job loss. Nonetheless, because several previous studies have used the HRS and some have found effects on specific physical conditions, we replicate the results for physical conditions in Table 2 using the HRS. In doing so, we have attempted to keep our sample selection and analysis file construction as similar as possible to our main approach with the MEPS data. These results, along with additional details of the HRS analysis are included in Appendix 2.

Briefly, when using the HRS, we continue to find little evidence that job loss increases the incidence of self-reported chronic conditions. Importantly, we also find substantial differences in point estimates depending on the specification used. When we use a measure of overall health at baseline to control for pre-existing differences in health between displaced and not displaced workers, many of the point estimates are larger, consistent with our findings based on MEPS data. Also consistent with our findings in Table 2, we find little evidence of increased likelihood of chronic physical conditions that might lay the groundwork for eventual increases in mortality. One exception to this pattern is that we do find, in a specification using HRS data identical to our preferred one from Table 2 a statistically significant increase in 
reports of hypertension. This seems to reflect the longer-time period over which we can follow individuals in the HRS. The largest effects of displacement on hypertension come in the HRS data from the period more than five years after job loss. Our focus here is on the shorter-term effects of job loss, but this does suggest a role for more gradual health changes as well.

\section{d. Restricted Definition of Job Displacement}

As a final alternative specification, we estimate models that add an interaction between the displacement variable and the reason for displacement (firm closing versus layoffs or job endings). This could be important in light of concerns that layoffs may disproportionately affect workers with low productivity, possibly linked to poor health. Thus, firm closings may provide a more exogenous employment shock than the full set of displacements. If this concern is important, we might expect to see smaller effects of displacement on health-related outcomes among those losing jobs in business closings. At the same time, displacements due to business closings may capture workers who lose jobs in particular industries or in particularly difficult local economic environments so are not perfectly comparable to the broader set of displacements.

Results from specifications in which job displacement is interacted with the reason for displacement are shown in Table 7. In short, we see evidence of smaller effects on insurance coverage and utilization after job loss from business closure, but few notable differences in the health coefficients. Thus, it does not appear that that laid off workers (for whom there is a greater possibility of negative, health related selection for layoff) drive the significant negative health effects we report here. 


\section{CONCLUSION}

In this paper, we use data from the Medical Expenditure Panel Survey to examine the short-term effects of job displacement on health outcomes, and to examine the role of health insurance shocks and changes medical care utilization in mediating these effects. By combining 16 panels of MEPS data, we generate a sample that includes almost 10,000 individuals that were involuntarily displaced from their main jobs between 1996 and 2012 - a much larger sample than other non-administrative datasets that have been used previously in the literature.

Using an empirical specification that includes both individual fixed effects and baseline health interacted with a linear time trend to account for unobservable individual characteristics that may be correlated with both health and the probability of job loss, we find that job displacement is associated with significant declines in self-rated physical and mental health, increases in activity limitations, and increased reports of anxiety or depression. There is no evidence of increases in specific chronic physical conditions including diabetes, arthritis, high cholesterol, heart disease, or hypertension. Focusing on a restricted sample that includes only individuals that held insurance through their employer in round 1, we find that these individuals are more likely to lose their insurance as a result of job loss (35.2 percent of the restricted sample experience a spell without insurance after job loss compared with 17 percent of the full sample), and to reduce their health care utilization (round-1 insurance holders experience a 5.3-percent decrease in the probability of a doctor's visit after displacement). However, we do not find larger health effects for the restricted sample of round 1 holders, which suggests that 
any short-term negative health effects for the full sample are not driven by reductions in medical care in the short-term.

The lack of immediate increases in physical health problems among those likely to lose insurance after job loss does not rule out the possibility that these reductions in insurance and utilization of health care over a longer time frame could have negative consequences for the longer-term health of affected workers. Previous work, for example, has shown that access to Medicaid and Medicare lowers health care utilization and mortality among children and the elderly (Currie and Gruber (1996), Card, Dobkin and Maestas (2008, 2009)). For displaced workers, however, only a minority faces a prolonged period without access to healthcare. The fact that we do see substantial reductions in health care utilization among the subset of displaced workers most likely to lose health insurance suggests that access to insurance, or perhaps continuity of care, could play an important role in generating long-term effects on mortality. Given the changes in coverage in the U.S. likely to come about as the Affordable Care Act is implemented, this suggests that an important area for study is the relationship between insurance status and utilization in the aftermath of job loss.

This brings us to our second main finding. Perhaps the most robust effects of job loss found here involve effects on mental health. A large literature establishes a strong association between stress and mortality, though a causal link from stress to long-term mortality has not been established (See, for example, Russ, et al. (2012) and citations therein). This is also consistent with arguments made by Sullivan and von Wachter (2009) who document a relationship between the extent of post-displacement income volatility (which may indicate 
prolonged uncertainty and stress) and mortality effects. While we do not see short-term increases in physical conditions that may be influenced by stress (such as diabetes or arthritis), prolonged mental health effects could lead to longer-term deterioration in physical health.

Job loss in the U.S. brings with it long-lasting reductions in earnings power, highly variable earnings, and a host of related effects on the health and well-being of individuals and their families. While the causal nature of this association has been well-established in the literature focusing on earnings effects of job loss, prior work on job loss and health outcomes has often lacked the longitudinal data and methods to establish causality. By controlling for individual fixed effects and health related trends, we show that job loss also results in decreased self-reported health, small increases in some chronic physical conditions, and marked declines in mental health. Future work should further explore the long-term effects of the stress of job loss on mental and physical health of workers, following up on the short-term indications found here that this is likely to be an important part of the relationship between job loss and long-term health. 


\section{References}

Baker, M., Stabile, M. \& Deri, C. (2004). What do Self-Reported, Objective Measures of Health Measure? The Journal of Human Resources, 39(4): 1067-1093.

Black, S. E., Devereux, P. J., \& Salvanes, K. G. (2012). Losing heart? The effect of job displacement on health. National Bureau of Economic Research Working Paper No. w18660.

Bergemann, A., Grönqvist, E., \& Gudbjörnsdottir, S. (2011) The effects of job displacement on the onset and progression of diabetes. Netspar Discussion Paper 03/2011-025.

Browning, M., Moller Dano, A., \& Heinesen, E. (2006) Job displacement and stress-related health outcomes. Health Economics, 15(10), 1061-1075.

Browning, M., \& Heinesen, E. (2012). Effect of job loss due to plant closure on mortality and hospitalization. Journal of Health Economics.

Card, David, Carlos Dobkin, and Nicole Maestas (2008). The impact of nearly universal insurance coverage on health care utilization and health: evidence from Medicare. American Economic Review, 98(5): 2242-2258.

Card, David, Carlos Dobkin, and Nicole Maestas (2009). Does Medicare save lives?" The Quarterly Journal of Economics 124, no. 2 (2009): 597-636.

Charles, K. K., and Stephens Jr, M. (2004). "Disability, Job Displacement and Divorce," Journal of Labor Economics, 22(2): 489-522.

Cohen, S., D. Janicki-Deverts, and G.E. Miller (2007) "Psychological Stress and Disease," Journal of the American Medical Association, 298 (14): 1685-1687.

Couch, K. A., and Placzek, D. W. (2010). Earnings losses of displaced workers revisited. The American Economic Review, 100(1), 572-589.

Currie, Janet, and Jonathan Gruber (1996) "Health insurance eligibility, utilization of medical care, and child health." The Quarterly Journal of Economics, 111(2): 431-466.

Eliason, M., \& Storrie, D. (2009). “Does job loss shorten life?" Journal of Human Resources, 44(2), 277-302.

Gallo, W. T., Bradley, E. H., Siegel, M., \& Kasl, S. V. (2000). Health effects of involuntary job loss among older workers: Findings from the health and retirement survey. The Journals of Gerontology Series B: Psychological Sciences and Social Sciences, 55(3), S131-S140. 
Grossman, M. (1972). On the concept of health capital and the demand for health. The Journal of Political Economy, 80(2), 223-255.

Gruber, J., \& Madrian, B. C. (1997). Employment separation and health insurance coverage. Journal of Public Economics, 66(3), 349-382.

Idler, E.L., \& Benyamini, Y. (1997). Self-Rated Health and Mortality: A Review of Twenty-Seven Community Studies, Journal of Health and Social Behavior, 38(1): 21-37.

Jacobson, L. S., LaLonde, R. J., \& Sullivan, D. G. (1993). Earnings losses of displaced workers. The American Economic Review, 685-709.

Lin, E. Y. (2005). Health insurance coverage and reemployment outcomes among older displaced workers. Contemporary Economic Policy, 23(4), 529-544.

Lindo, J. M. (2010). Are Children Really Inferior Goods? Evidence from Displacement-driven Income Shocks. Journal of Human Resources, 45(2), 301-327.

Lindo, J. M. (2011). Parental job loss and infant health. Journal of Health Economics, 30(5), 869879.

Oreopoulos, P., Page, M. E., \& Stevens, A. H. (2006). The intergenerational effects of compulsory schooling. Journal of Labor Economics, 24(4), 729-760.

Rege, M., Telle, K., \& Votruba, M. (2009). The effect of plant downsizing on disability pension utilization. Journal of the European Economic Association, 7(4), 754-785.

Ruhm, C. J. (1991). Are workers permanently scarred by job displacements?. The American Economic Review, 81(1), 319-324.

Russ, T., E. Stamatakis, M. Hammer, J. M. Starr, M. Kivimaki, and D. Batty (2012). Association between psychological distress and mortality: individual participant pooled analysis of 10 prospective cohort studies. BMJ 342:1-14.

Salm, M. (2009). Does job loss cause ill health?. Health Economics, 18(9), 1075-1089.

Schmieder, J. F., Von Wachter, T., \& Bender, S. (2010). The long-term impact of job displacement in Germany during the 1982 recession o $\mathrm{n}$ earnings, income, and employment. IAB discussion paper No 2010, 1.

Stevens, A. H. (1997). Persistent effects of job displacement: The importance of multiple job losses. Journal of Labor Economics, 165-188. 
Stevens, A. H., \& Schaller, J. (2011). Short-run effects of parental job loss on children's academic achievement. Economics of Education Review, 30(2), 289-299.

Strully, K. W. (2009). Job loss and health in the US labor market. Demography, 46(2), 221-246.

Sullivan, D., \& Von Wachter, T. (2009). Job displacement and mortality: An analysis using administrative data. The Quarterly Journal of Economics, 124(3), 1265-1306.

Wolfers, J. (2003). Did Unilateral Divorce Laws Raise Divorce Rates? A Reconciliation and New Results. NBER Working Paper No. 10014. 


\section{Appendix 1: Replicating Health Conditions Results in the HRS}

Given the fairly large number of papers that have utilized the Health and Retirement Study (HRS) to examine effects of job loss on a variety of individual conditions, we have repeated our main analysis of conditions from Table 2 using a sample from the HRS. In doing so, we have attempted to keep our sample selection and analysis file construction as similar as possible to our main approach with the MEPS data. We use waves 1 through 10 of the HRS, spanning reports taken between 1992 and 2010. Because data on individual's history of job losses (going back prior to the previous wave) is asked only in wave 1, we utilize only individuals who were in the initial cohorts of the HRS. This gives us a sample of approximately 77,000 person years, with roughly 2600 workers who experienced a displacement sometime between 1993 and 2010. Importantly, the average age at displacement in the HRS sample is approximately 61 years.

Results of both an OLS regression with controls for a baseline (initial wave) health measure and our specification including fixed-effects and a trend interacted with baseline health, are shown in Appendix Table 3. The first column of that table also shows means for the dependent variables in the initial wave, and highlights the dramatic changes in health conditions between the MEPS and HRS samples, likely to be explained by the age differences between the two samples. For example, roughly 28 percent of the HRS sample report having arthritis, compared to just 8 percent in the MEPS data.

We view these results as quite consistent with our main findings in Table 2. Specifically, there is evidence here of the importance of including individual fixed-effects and trends, as several of the point estimates are reduced substantially from the OLS specification in column 2 
to our preferred estimates in column 3. At a minimum, this suggests caution in assuming that a baseline health control is equivalent to longitudinal methods that control for initial levels of the specific condition for which displacement effects are being estimated. 
Tables

Table 1

Summary Statistics

\begin{tabular}{|c|c|c|c|c|}
\hline \multirow[b]{2}{*}{ Demographic Characteristics } & \multicolumn{2}{|l|}{$\begin{array}{c}\text { Never } \\
\text { Displaced }\end{array}$} & \multicolumn{2}{|l|}{ Displaced } \\
\hline & & & & \\
\hline Male & 0.526 & & 0.572 & \\
\hline Age & 41.03 & & 38.22 & \\
\hline Black, Non-Hispanic & 0.107 & & 0.134 & \\
\hline Other Race, Non-Hispanic & 0.059 & & 0.055 & \\
\hline Hispanic & 0.120 & & 0.168 & \\
\hline High School Dropout & 0.097 & & 0.157 & \\
\hline High School Graduate & 0.282 & & 0.319 & \\
\hline \multirow[t]{2}{*}{ Any College } & 0.558 & & 0.480 & \\
\hline & Round 1 & Round 5 & Round 1 & Round 5 \\
\hline \multicolumn{5}{|l|}{ General and Mental Health } \\
\hline Health Fair or Poor & 0.083 & 0.071 & 0.107 & 0.099 \\
\hline Work Limitation & 0.022 & 0.024 & 0.026 & 0.036 \\
\hline Recreational Limitation & 0.017 & 0.016 & 0.018 & 0.025 \\
\hline Mental Health Fair or Poor & 0.032 & 0.038 & 0.051 & 0.066 \\
\hline Depression or Anxiety & 0.071 & 0.153 & 0.086 & 0.194 \\
\hline \multicolumn{5}{|l|}{ Medical Conditions } \\
\hline Arthritis & 0.087 & 0.153 & 0.086 & 0.157 \\
\hline Diabetes & 0.038 & 0.051 & 0.038 & 0.053 \\
\hline High Cholesterol & 0.076 & 0.111 & 0.062 & 0.094 \\
\hline Heart Condition & 0.030 & 0.066 & 0.026 & 0.058 \\
\hline Hypertension & 0.117 & 0.156 & 0.099 & 0.137 \\
\hline Trauma/Injury & 0.070 & 0.032 & 0.077 & 0.038 \\
\hline Infectious Disease & 0.226 & 0.100 & 0.228 & 0.094 \\
\hline Cancer & 0.014 & 0.027 & 0.010 & 0.020 \\
\hline \multicolumn{5}{|l|}{ Insurance Coverage } \\
\hline Any Health Insurance & 0.841 & 0.837 & 0.687 & 0.597 \\
\hline Private Health Insurance & 0.804 & 0.801 & 0.620 & 0.517 \\
\hline Public Health Insurance & 0.057 & 0.053 & 0.082 & 0.094 \\
\hline Uninsured During Round & 0.186 & 0.170 & 0.350 & 0.427 \\
\hline \multicolumn{5}{|l|}{ Health Care Utilization } \\
\hline Any Office Visit & 0.448 & 0.375 & 0.398 & 0.326 \\
\hline Expenditures on Office Visits & 189.00 & 208.26 & 154.567 & 171.167 \\
\hline Any Emergency Room (ER) Visit & 0.038 & 0.030 & 0.050 & 0.042 \\
\hline Expenditures on ER Visits & 31.69 & 30.76 & 33.550 & 45.342 \\
\hline Any Prescription (Rx) & 0.431 & 0.386 & 0.377 & 0.328 \\
\hline Expenditures on Prescription Drugs & 130.02 & 182.54 & 111.196 & 150.751 \\
\hline Observations (Unweighted) & 97885 & 84235 & 10631 & 9668 \\
\hline
\end{tabular}

Notes: The data are from the 1996 through 2012 waves of the Household Component of the Medical Expenditure Panel Survey. The sample includes individuals aged 21 to 65 that are employed in the first round of the survey. Observations are weighted using MEPS person-level sampling weights. With two exceptions, the differences between means for displaced and never displaced workers in Round 1 are statistically significant at the 5 percent level. The exceptions are arthritis and diabetes. 
Table 2

Effects of Job Displacement on Health

\begin{tabular}{|c|c|c|c|c|}
\hline & \multirow[b]{2}{*}{ Round 1 Mean } & \multicolumn{3}{|c|}{ Regression Specification } \\
\hline & & $\begin{array}{l}\text { OLS with Baseline } \\
\text { Controls }\end{array}$ & Fixed Effects & $\begin{array}{c}\text { Fixed Effects With } \\
\text { Baseline } \\
\text { Health*Trend }\end{array}$ \\
\hline \multicolumn{5}{|l|}{ General Health } \\
\hline Health Fair or Poor & 0.085 & $\begin{array}{l}0.0114^{* * *} \\
(0.003)\end{array}$ & $\begin{array}{l}0.0031 \\
(0.003)\end{array}$ & $\begin{array}{l}0.0137^{* * *} \\
(0.003)\end{array}$ \\
\hline $\begin{array}{l}\text { Limitation on Work, } \\
\text { Housework, or School }\end{array}$ & 0.022 & $\begin{array}{l}0.0107^{* * *} \\
(0.002)\end{array}$ & $\begin{array}{l}0.0056^{*} \\
(0.002)\end{array}$ & $\begin{array}{l}0.0057^{* *} \\
(0.002)\end{array}$ \\
\hline $\begin{array}{l}\text { Limitation on Social or } \\
\text { Recreational Activites }\end{array}$ & 0.017 & $\begin{array}{l}0.0066^{* * *} \\
(0.002)\end{array}$ & $\begin{array}{l}0.0043^{*} \\
(0.002)\end{array}$ & $\begin{array}{l}0.0048^{*} \\
(0.002)\end{array}$ \\
\hline \multicolumn{5}{|l|}{ Health Conditions } \\
\hline Arthritis & 0.087 & $\begin{array}{l}0.0188^{* * *} \\
(0.004)\end{array}$ & $\begin{array}{l}0.0053^{*} \\
(0.002)\end{array}$ & $\begin{array}{l}0.0015 \\
(0.002)\end{array}$ \\
\hline Diabetes & 0.038 & $\begin{array}{l}0.0043 \\
(0.003)\end{array}$ & $\begin{array}{l}0.0031^{* *} \\
(0.001)\end{array}$ & $\begin{array}{l}0.0016 \\
(0.001)\end{array}$ \\
\hline High Cholesterol & 0.075 & $\begin{array}{l}0.0007 \\
(0.004)\end{array}$ & $\begin{array}{l}0.0018 \\
(0.002)\end{array}$ & $\begin{array}{l}-0.0006 \\
(0.002)\end{array}$ \\
\hline Heart Condition & 0.029 & $\begin{array}{l}0.0051 \\
(0.003)\end{array}$ & $\begin{array}{l}0.0006 \\
(0.001)\end{array}$ & $\begin{array}{l}-0.0026 \\
(0.001)\end{array}$ \\
\hline Hypertension & 0.115 & $\begin{array}{l}0.0005 \\
(0.004)\end{array}$ & $\begin{array}{l}0.0016 \\
(0.002)\end{array}$ & $\begin{array}{l}-0.0014 \\
(0.002)\end{array}$ \\
\hline Trauma & 0.071 & $\begin{array}{l}-0.0059 * * \\
(0.002)\end{array}$ & $\begin{array}{l}-0.0071^{*} \\
(0.003)\end{array}$ & $\begin{array}{l}-0.0051 \\
(0.003)\end{array}$ \\
\hline Infectious Disease & 0.226 & $\begin{array}{l}-0.0322^{* * *} \\
(0.003)\end{array}$ & $\begin{array}{l}-0.0297^{* * *} \\
(0.005)\end{array}$ & $\begin{array}{l}-0.0169 * * * \\
(0.005)\end{array}$ \\
\hline Cancer & 0.014 & $\begin{array}{l}-0.0003 \\
(0.002)\end{array}$ & $\begin{array}{l}-0.0007 \\
(0.001)\end{array}$ & $\begin{array}{l}-0.0015 \\
(0.001)\end{array}$ \\
\hline \multicolumn{5}{|l|}{ Mental Health } \\
\hline Mental Health Fair or Poor & 0.034 & $\begin{array}{l}0.0191 * * * \\
(0.002)\end{array}$ & $\begin{array}{l}0.0091 * * * \\
(0.003)\end{array}$ & $\begin{array}{l}0.0139 * * * \\
(0.003)\end{array}$ \\
\hline Depression or Anxiety & 0.073 & $\begin{array}{l}0.0541^{* * *} \\
(0.005)\end{array}$ & $\begin{array}{l}0.0245^{* * *} \\
(0.003)\end{array}$ & $\begin{array}{l}0.0164^{* * *} \\
(0.003)\end{array}$ \\
\hline \multicolumn{5}{|c|}{$\begin{array}{l}\text { Notes: The sample includes } 108,516 \text { individuals aged } 21-65 \text { who were employed in the first round of the } \\
\text { survey, 10,631 of whom were displaced after the first round. The number of person-round observations } \\
\text { is } 497,997, \text { except for in the regressions with activity limitations as the dependent variable, which are } \\
\text { estimated with } 296,673 \text { person-round observations (Rounds } 1,3 \text {, and } 5 \text { only). Standard errors (in } \\
\text { parentheses) are clustered at the individual level. * } p<.1 * * p<.05 * * * \text { p<.01. Estimates are weighted } \\
\text { using the MEPS person-level sampling weight. "Displaced" indicates involuntary displacement prior to the } \\
\text { interview. OLS regressions include dummies for Round } 1 \text { health and mental health ( } 1=\text { excellent, } 2=\text { very } \\
\text { good, } 3=\text { good, } 4 \text { = fair, } 5 \text { = poor), race/ethnicity (non-Hispanic black, non-Hispanic other race, Hispanic), } \\
\text { and educational attainment (high school graduate, college graduate). All regressions include age and } \\
\text { calendar year fixed effects. Results in column } 4 \text { include baseline health and mental health interacted with } \\
\text { linear time trends }\end{array}$} \\
\hline
\end{tabular}


Table 3

Time-Varying Effects of Job Displacement on Health

\begin{tabular}{|c|c|c|c|c|c|c|c|c|}
\hline \multicolumn{9}{|c|}{ Panel A: General and Mental Health Outcomes } \\
\hline \multicolumn{3}{|c|}{ Health } & \multirow{2}{*}{$\begin{array}{l}\text { Recreational } \\
\text { Limitation }\end{array}$} & \multirow{2}{*}{$\begin{array}{l}\text { Mental Health } \\
\text { Fair or Poor }\end{array}$} & \multirow{2}{*}{$\begin{array}{c}\text { Depression or } \\
\text { Anxiety }\end{array}$} & & & \\
\hline Displaced: & Fair or Poor & Work Limitation & & & & & & \\
\hline \multirow[t]{2}{*}{ Next Round } & -0.0011 & 0.0056 & 0.0071 & 0.0010 & 0.0057 & & & \\
\hline & $(0.004)$ & $(0.004)$ & $(0.004)$ & $(0.003)$ & $(0.003)$ & & & \\
\hline \multirow[t]{2}{*}{ Current Round } & $0.0119 * *$ & -0.0020 & -0.0005 & $0.0150 * * *$ & $0.0165 * * *$ & & & \\
\hline & $(0.004)$ & $(0.003)$ & $(0.003)$ & $(0.004)$ & $(0.004)$ & & & \\
\hline \multirow[t]{2}{*}{ Previous Round } & $0.0140 * * *$ & $0.0126 * * *$ & $0.0116 * * *$ & $0.0140 * * *$ & $0.0226 * * *$ & & & \\
\hline & $(0.004)$ & $(0.004)$ & $(0.003)$ & $(0.004)$ & $(0.004)$ & & & \\
\hline \multicolumn{9}{|c|}{ Panel B: Medical Conditions } \\
\hline & & & & High & & & Infectious & \\
\hline Displaced: & Arthritis & Diabetes & Heart Condition & Cholesterol & Hypertension & Trauma & Disease & Cancer \\
\hline \multirow[t]{2}{*}{ Next Round } & $0.0054^{*}$ & 0.0010 & 0.0011 & -0.0024 & -0.0014 & 0.0019 & -0.0015 & -0.0013 \\
\hline & $(0.003)$ & $(0.001)$ & $(0.002)$ & $(0.002)$ & $(0.002)$ & $(0.005)$ & $(0.007)$ & $(0.001)$ \\
\hline \multirow[t]{2}{*}{ Current Round } & 0.0048 & 0.0018 & 0.0012 & -0.0037 & -0.0019 & 0.0002 & $-0.0221 * * *$ & -0.0019 \\
\hline & $(0.003)$ & $(0.002)$ & $(0.002)$ & $(0.002)$ & $(0.002)$ & $(0.005)$ & $(0.006)$ & $(0.001)$ \\
\hline \multirow[t]{2}{*}{ Previous Round } & 0.0045 & 0.0024 & -0.0011 & -0.0044 & -0.0025 & -0.0077 & $-0.0138 *$ & -0.0026 \\
\hline & $(0.004)$ & $(0.002)$ & $(0.003)$ & $(0.002)$ & $(0.003)$ & $(0.005)$ & (0.007) & $(0.001)$ \\
\hline
\end{tabular}

Notes: The sample includes 108,516 individuals aged 21-65 who were employed in the first round of the survey, 10,631 of whom were displaced after the first round. The number of person-round observations is 497,997, except for in the regressions with activity limitations as the dependent variable, which are estimated with data from rounds 1,3 , and 5 only. Standard errors (in parentheses) are clustered at the individual level. * $p<.1 * * p<.05 * * * p<.01$. Estimates are weighted using MEPS person-level sampling weight. All regressions include age and calendar year fixed effects and baseline health and mental health interacted with time trends. "Current round" is an indicator for job displacement that has occured during the reference period immediately prior to the interview. In Panel B, "current round" implies that job displacement and medical conditions are observed during the same reference period. 
Table 4

Effects of Job Displacement on Health Insurance Status and Health Care Utilization

\begin{tabular}{|c|c|c|c|c|}
\hline \multicolumn{5}{|c|}{ Panel A: Insurance Status } \\
\hline Displaced: & $\begin{array}{l}\text { Any Health } \\
\text { Insurance }\end{array}$ & $\begin{array}{l}\text { Private Health } \\
\text { Insurance }\end{array}$ & $\begin{array}{l}\text { Public Health } \\
\text { Insurance }\end{array}$ & $\begin{array}{l}\text { Uninsured } \\
\text { During Round }\end{array}$ \\
\hline Next Round & $\begin{array}{l}-0.0228^{* * *} \\
(0.005)\end{array}$ & $\begin{array}{l}-0.0230 * * * \\
(0.005)\end{array}$ & $\begin{array}{l}0.0004 \\
(0.003)\end{array}$ & $\begin{array}{l}0.0238^{* * *} \\
(0.005)\end{array}$ \\
\hline Current Round & $\begin{array}{l}-0.1302^{* * *} \\
(0.007)\end{array}$ & $\begin{array}{l}-0.1445^{* * *} \\
(0.007)\end{array}$ & $\begin{array}{l}0.0134^{* * *} \\
(0.003)\end{array}$ & $\begin{array}{l}0.1698^{* * *} \\
(0.007)\end{array}$ \\
\hline Previous Round & $\begin{array}{l}-0.0963^{* * *} \\
(0.007)\end{array}$ & $\begin{array}{l}-0.1127^{* * *} \\
(0.007)\end{array}$ & $\begin{array}{l}0.0144 * * * \\
(0.004)\end{array}$ & $\begin{array}{l}0.1183^{* * *} \\
(0.007)\end{array}$ \\
\hline
\end{tabular}

\section{Panel B: Health Care Utilization}

\begin{tabular}{|c|c|c|c|c|c|c|}
\hline Displaced: & Any Office Visit & $\begin{array}{c}\text { Office } \\
\text { Expenditures }\end{array}$ & $\begin{array}{l}\text { Any Emergency } \\
\text { Room (ER) Visit }\end{array}$ & ER Expenditures & $\begin{array}{c}\text { Any } \\
\text { Prescription } \\
(\mathrm{Rx})\end{array}$ & Rx Expenditures \\
\hline Next Round & $\begin{array}{l}0.0120 \\
(0.007)\end{array}$ & $\begin{array}{l}5.5475 \\
(16.360)\end{array}$ & $\begin{array}{l}0.0051 \\
(0.004)\end{array}$ & $\begin{array}{l}-1.0085 \\
(6.295)\end{array}$ & $\begin{array}{l}0.0097 \\
(0.006)\end{array}$ & $\begin{array}{l}-7.8546 \\
(9.677)\end{array}$ \\
\hline Current Round & $\begin{array}{l}0.0282^{* * *} \\
(0.008)\end{array}$ & $\begin{array}{l}17.3551 \\
(18.019)\end{array}$ & $\begin{array}{l}0.0056 \\
(0.004)\end{array}$ & $\begin{array}{l}1.9820 \\
(6.800)\end{array}$ & $\begin{array}{l}0.0183^{* *} \\
(0.007)\end{array}$ & $\begin{array}{l}-8.1899 \\
(9.818)\end{array}$ \\
\hline Previous Round & $\begin{array}{l}-0.0253^{* *} \\
(0.008)\end{array}$ & $\begin{array}{l}-39.3156 \\
(32.722)\end{array}$ & $\begin{array}{l}0.0004 \\
(0.004)\end{array}$ & $\begin{array}{l}2.1800 \\
(8.232)\end{array}$ & $\begin{array}{l}-0.0203^{* *} \\
(0.007)\end{array}$ & $\begin{array}{l}-54.4244 * * * \\
(11.240)\end{array}$ \\
\hline
\end{tabular}

Notes: The sample includes 108,516 individuals aged 21-65 who were employed in the first round of the survey, 10,631 of whom were displaced after the first round. The number of person-round observations is 497,997, except for in the regressions with activity limitations as the dependent variable, which are estimated with data from rounds 1,3 , and 5 only. Standard errors (in parentheses) are clustered at the individual level. ${ }^{*} p<.1{ }^{* *} p<.05^{* * *} p<.01$. Estimates are weighted using MEPS person-level sampling weight. "Any Insurance," "Private Insurance," and "Public Insurance" represent current insurance status during the month of the interview, while "Ever Uninsured" indicates whether an individual was unemployed for at least one month during the current survey round. All utilization variables refer to the current survey round. All regressions include age and calendar year fixed effects and baseline health and mental health interacted with time trends. 
Table 5

Job Displacement, Insurance Status, Utilization, and Health: Round 1 Insurance Holders

\begin{tabular}{lllll} 
Panel A: Insurance Status & & \multicolumn{2}{l}{ Any Health } \\
Insurance & $\begin{array}{c}\text { Private Health } \\
\text { Insurance }\end{array}$ & $\begin{array}{c}\text { Public Health } \\
\text { Insurance }\end{array}$ & $\begin{array}{c}\text { Uninsured } \\
\text { During Round }\end{array}$ \\
Next Round & $-0.0409^{* * *}$ & $-0.0397^{* * *}$ & 0.0014 & $0.0291^{* * *}$ \\
& $(0.006)$ & $(0.007)$ & $(0.003)$ & $(0.007)$ \\
Current Round & $-0.3051^{* * *}$ & $-0.3241^{* * *}$ & $0.0165^{* * *}$ & $0.3521^{* * *}$ \\
& $(0.011)$ & $(0.011)$ & $(0.004)$ & $(0.011)$ \\
Previous Round & $-0.2724^{* * *}$ & $-0.2977^{* * *}$ & $0.0207^{* * *}$ & $0.3049^{* * *}$ \\
& $(0.010)$ & $(0.011)$ & $(0.005)$ & $(0.011)$
\end{tabular}

Panel B: Health Care Utilization

\begin{tabular}{|c|c|c|c|c|c|c|}
\hline Displaced: & Any Office Visit & $\begin{array}{c}\text { Office } \\
\text { Expenditures }\end{array}$ & $\begin{array}{l}\text { Any Emergency } \\
\text { Room (ER) Visit }\end{array}$ & ER Expenditures & $\begin{array}{c}\text { Any } \\
\text { Prescription } \\
\text { (Rx) }\end{array}$ & Rx Expenditures \\
\hline Next Round & $\begin{array}{l}0.0145 \\
(0.012)\end{array}$ & $\begin{array}{l}43.7235 \\
(27.774)\end{array}$ & $\begin{array}{l}0.0067 \\
(0.006)\end{array}$ & $\begin{array}{l}4.2551 \\
(11.343)\end{array}$ & $\begin{array}{l}0.0240^{*} \\
(0.010)\end{array}$ & $\begin{array}{l}2.4186 \\
(14.359)\end{array}$ \\
\hline Current Round & $\begin{array}{l}0.0087 \\
(0.013)\end{array}$ & $\begin{array}{l}56.8140 \\
(32.694)\end{array}$ & $\begin{array}{l}-0.0053 \\
(0.006)\end{array}$ & $\begin{array}{l}-13.9829 \\
(10.539)\end{array}$ & $\begin{array}{l}0.0043 \\
(0.011)\end{array}$ & $\begin{array}{l}-1.1725 \\
(15.182)\end{array}$ \\
\hline Previous Round & $\begin{array}{l}-0.0661 * * * \\
(0.013)\end{array}$ & $\begin{array}{l}-18.2005 \\
(73.936)\end{array}$ & $\begin{array}{l}-0.0072 \\
(0.006)\end{array}$ & $\begin{array}{l}-13.8392 \\
(11.017)\end{array}$ & $\begin{array}{l}-0.0421 * * * \\
(0.011)\end{array}$ & $\begin{array}{l}-62.0749 * * * \\
(15.205)\end{array}$ \\
\hline
\end{tabular}

Panel C: General and Mental Health Outcomes

\begin{tabular}{|c|c|c|c|c|c|c|c|c|}
\hline \multirow{2}{*}{\multicolumn{3}{|c|}{ Health }} & \multirow{3}{*}{$\begin{array}{l}\text { Recreational } \\
\text { Limitation }\end{array}$} & \multirow{3}{*}{$\begin{array}{l}\text { Mental Health } \\
\text { Fair or Poor }\end{array}$} & \multirow{3}{*}{$\begin{array}{c}\text { Depression or } \\
\text { Anxiety }\end{array}$} & & & \\
\hline & & & & & & & & \\
\hline Displaced: & Fair or Poor & Work Limitation & & & & & & \\
\hline \multirow[t]{2}{*}{ Next Round } & -0.0001 & 0.0041 & 0.0052 & 0.0030 & 0.0034 & & & \\
\hline & $(0.006)$ & $(0.006)$ & $(0.006)$ & $(0.005)$ & $(0.005)$ & & & \\
\hline \multirow[t]{2}{*}{ Current Round } & 0.0081 & 0.0019 & 0.0015 & $0.0198 * *$ & $0.0160 * *$ & & & \\
\hline & $(0.006)$ & $(0.005)$ & $(0.005)$ & $(0.006)$ & $(0.006)$ & & & \\
\hline \multirow[t]{2}{*}{ Previous Round } & 0.0116 & 0.0064 & 0.0043 & $0.0172 * *$ & $0.0263^{* * *}$ & & & \\
\hline & $(0.006)$ & $(0.005)$ & $(0.006)$ & $(0.006)$ & $(0.007)$ & & & \\
\hline \multicolumn{9}{|c|}{ Panel D: Medical Conditions } \\
\hline & & & & High & & & Infectious & \\
\hline Displaced: & Arthritis & Diabetes & Heart Condition & Cholesterol & Hypertension & Trauma & Disease & Cancer \\
\hline \multirow[t]{2}{*}{ Next Round } & 0.0014 & 0.0008 & 0.0004 & -0.0020 & -0.0015 & 0.0032 & -0.0011 & -0.0002 \\
\hline & $(0.004)$ & $(0.002)$ & $(0.003)$ & $(0.003)$ & $(0.003)$ & $(0.008)$ & $(0.011)$ & $(0.002)$ \\
\hline \multirow[t]{2}{*}{ Current Round } & -0.0006 & 0.0010 & 0.0001 & $-0.0060 *$ & -0.0030 & -0.0032 & $-0.0384 * * *$ & -0.0001 \\
\hline & $(0.004)$ & $(0.002)$ & $(0.003)$ & $(0.003)$ & $(0.003)$ & $(0.007)$ & $(0.010)$ & $(0.002)$ \\
\hline \multirow[t]{2}{*}{ Previous Round } & -0.0030 & 0.0015 & -0.0012 & $-0.0074^{*}$ & -0.0047 & -0.0121 & $-0.0344 * * *$ & -0.0014 \\
\hline & $(0.005)$ & $(0.003)$ & $(0.004)$ & $(0.004)$ & $(0.004)$ & $(0.007)$ & $(0.010)$ & $(0.002)$ \\
\hline
\end{tabular}

Notes: The sample includes 56,228 individuals who held insurance through their employer in the first round of the survey, 3,805 of whom were displaced after the first round. The number of person-round observations is 259,496 , except for in the regressions with activity limitations as the dependent variable, which are estimated with data from rounds 1,3 , and 5 only. Standard errors (in parentheses) are clustered at the individual level. * $\mathrm{p}<.1{ }^{* *} \mathrm{p}<.05 * * * \mathrm{p}<.01$. Estimates are weighted using MEPS person-level sampling weight. "Any Insurance," "Private Insurance," and "Public Insurance" represent current insurance status during the month of the interview, while "Ever Uninsured" indicates whether an individual was unemployed for at least one month during the current survey round. All utilization variables refer to the current survey round. All regressions include age and calendar year fixed effects and baseline health and mental health interacted with time trends. 
Table 6

Job Displacement, Insurance Status, Utilization, and Health: People with Chronic Conditions in Round 1

\begin{tabular}{|c|c|c|c|c|}
\hline \multicolumn{5}{|c|}{ Panel A: Insurance Status } \\
\hline Displaced: & $\begin{array}{l}\text { Any Health } \\
\text { Insurance }\end{array}$ & $\begin{array}{c}\text { Private Health } \\
\text { Insurance }\end{array}$ & $\begin{array}{l}\text { Public Health } \\
\text { Insurance }\end{array}$ & $\begin{array}{c}\text { Uninsured } \\
\text { During Round }\end{array}$ \\
\hline Next Round & $\begin{array}{l}-0.0210^{*} \\
(0.009)\end{array}$ & $\begin{array}{l}-0.0247^{* *} \\
(0.009)\end{array}$ & $\begin{array}{l}0.0015 \\
(0.005)\end{array}$ & $\begin{array}{l}0.0323 * * * \\
(0.009)\end{array}$ \\
\hline Current Round & $\begin{array}{l}-0.1334^{* * *} \\
(0.012)\end{array}$ & $\begin{array}{l}-0.1494^{* * *} \\
(0.012)\end{array}$ & $\begin{array}{l}0.0156^{* *} \\
(0.006)\end{array}$ & $\begin{array}{l}0.1723 * * * \\
(0.013)\end{array}$ \\
\hline revious Round & $\begin{array}{l}-0.1023^{* * *} \\
(0.013)\end{array}$ & $\begin{array}{l}-0.1151^{* * *} \\
(0.013)\end{array}$ & $\begin{array}{l}0.0118 \\
(0.007)\end{array}$ & $\begin{array}{l}0.1200^{* * *} \\
(0.013)\end{array}$ \\
\hline
\end{tabular}

Panel B: Health Care Utilization

\begin{tabular}{lllllll} 
& \multicolumn{2}{c}{$\begin{array}{c}\text { Office } \\
\text { Displaced: }\end{array}$} & Any Office Visit & $\begin{array}{l}\text { Any Emergency } \\
\text { Expenditures }\end{array}$ & $\begin{array}{c}\text { ER } \\
\text { Room (ER) Visit }\end{array}$ & \multicolumn{2}{c}{$\begin{array}{c}\text { Any Prescription } \\
\text { Expenditures }\end{array}$} & (Rx) & Rx Expenditures \\
Next Round & -0.0090 & -16.4526 & 0.0034 & -27.7369 & -0.0058 & -17.2893 \\
& $(0.014)$ & $(42.327)$ & $(0.008)$ & $(15.576)$ & $(0.012)$ & $(25.275)$ \\
Current Round & 0.0214 & -27.9781 & 0.0062 & -4.1854 & -0.0017 & -22.1592 \\
& $(0.015)$ & $(42.774)$ & $(0.009)$ & $(17.360)$ & $(0.013)$ & $(25.227)$ \\
Previous Round & $-0.0363^{*}$ & $-145.789 * * *$ & 0.0051 & -13.8675 & $-0.0384^{* *}$ & $-111.860^{* * *}$ \\
& $(0.015)$ & $(40.644)$ & $(0.008)$ & $(16.300)$ & $(0.014)$ & $(31.761)$ \\
\hline
\end{tabular}

Panel C: General and Mental Health Outcomes

Health Recreational Mental Health Depression or

Displaced: $\quad$ Fair or Poor Work Limitation Limitation Fair or Poor Anxiety

$\begin{array}{llllll}\text { Next Round } & -0.0001 & 0.0076 & 0.0141 & -0.0060 & 0.0128 \\ & (0.009) & (0.009) & (0.010) & (0.008) & (0.007) \\ \text { Current Round } & 0.0118 & -0.0032 & -0.0006 & 0.0050 & 0.0211^{* *} \\ & (0.010) & (0.008) & (0.008) & (0.008) & (0.008) \\ \text { Previous Round } & 0.0157 & 0.0216^{*} & 0.0299^{* *} & 0.0119 & 0.0321^{* * *} \\ & (0.010) & (0.010) & (0.010) & (0.008) & (0.009)\end{array}$

Notes: The sample includes 23,009 individuals who had a chronic physical health condition (diabetes, heart condition, hypertension, arthritis, or cancer) in the first round of the survey, 2,048 of whom were displaced after the first round. The number of person-round observations is 104,546, except for the regressions with activity limitations as the dependent variable, which are estimated with data from rounds 1,3, and 5 only. Standard errors (in parentheses) are clustered at the individual level. ${ }^{*} p<.1 * * p<.05 * * * p<.01$. Estimates are weighted using MEPS person-level sampling weight. "Any Insurance," "Private Insurance," and "Public Insurance" represent current insurance status during the month of the interview, while "Ever Uninsured" indicates whether an individual was unemployed for at least one month during the current survey round. All utilization variables refer to the current survey round. All regressions include age and calendar vear fixed effects and baseline health and mental health interacted with time trends. 
Table 7

Job Displacement, Insurance Status, Utilization, and Health, by Type of Displacement

\begin{tabular}{lllll}
\hline \hline Panel A: Insurance Status & \multicolumn{1}{c}{ Any Health } & Private Health & Public Health \\
& Insurance & \multicolumn{1}{c}{$\begin{array}{c}\text { Uninsured } \\
\text { Insurance }\end{array}$} & $\begin{array}{c}\text { Insurance } \\
\text { During Round }\end{array}$ \\
Job Ended or Laid Off & $-0.1140^{* * *}$ & $-0.1302^{* * *}$ & $0.0139^{* * *}$ & $0.1454^{* * *}$ \\
& $(0.006)$ & $(0.006)$ & $(0.003)$ & $(0.006)$ \\
Business Sold or Closed & $-0.0516^{* * *}$ & $-0.0637^{* * *}$ & $0.0127^{* *}$ & $0.0765^{* * *}$ \\
& $(0.008)$ & $(0.008)$ & $(0.004)$ & $(0.009)$ \\
\hline
\end{tabular}

Panel B: Health Care Utilization

\begin{tabular}{|c|c|c|c|c|c|c|}
\hline & Any Office Visit & $\begin{array}{c}\text { Office } \\
\text { Expenditures }\end{array}$ & $\begin{array}{l}\text { Any Emergency } \\
\text { Room (ER) Visit }\end{array}$ & ER Expenditures & $\begin{array}{l}\text { Any Prescription } \\
\qquad(\mathrm{Rx})\end{array}$ & Rx Expenditures \\
\hline Job Ended or Laid Off & $\begin{array}{l}-0.0118 \\
(0.006)\end{array}$ & $\begin{array}{l}-13.5241 \\
(22.742)\end{array}$ & $\begin{array}{l}-0.0007 \\
(0.003)\end{array}$ & $\begin{array}{l}0.5389 \\
(5.388)\end{array}$ & $\begin{array}{l}-0.0114^{*} \\
(0.006)\end{array}$ & $\begin{array}{l}-31.0894 * * * \\
(8.462)\end{array}$ \\
\hline Business Sold or Closed & $\begin{array}{l}0.0082 \\
(0.011)\end{array}$ & $\begin{array}{l}-22.7239 \\
(21.746)\end{array}$ & $\begin{array}{l}0.0019 \\
(0.005)\end{array}$ & $\begin{array}{l}9.4537 \\
(12.704)\end{array}$ & $\begin{array}{l}0.0040 \\
(0.010)\end{array}$ & $\begin{array}{l}-17.8151 \\
(9.795)\end{array}$ \\
\hline
\end{tabular}

\section{Panel C: Health Outcomes}

$\begin{array}{cccc}\text { Health } & \text { Recreational } \\ \text { Fair or Poor Wontal Health } & \text { Depression or } \\ \text { Limitation } & \text { Fair or Poor } & \text { Anxiety }\end{array}$

Job Ended or Laid Off

$\begin{array}{lllll}0.0146^{* * *} & 0.0055^{*} & 0.0049 * & 0.0151^{* * *} & 0.0150^{* * *} \\ (0.003) & (0.003) & (0.002) & (0.003) & (0.003) \\ 0.0106^{*} & 0.0063 & 0.0046 & 0.0102^{*} & 0.0205^{* * *} \\ (0.005) & (0.004) & (0.004) & (0.004) & (0.006)\end{array}$

Business Sold or Closed

\begin{tabular}{|c|c|c|c|c|c|c|c|c|}
\hline & Arthritis & Diabetes & Heart Condition & Cholesterol & Hypertension & Trauma & Disease & Cance \\
\hline Job Ended or Laid Off & $\begin{array}{l}0.0003 \\
(0.002)\end{array}$ & $\begin{array}{l}0.0014 \\
(0.001)\end{array}$ & $\begin{array}{l}0.0002 \\
(0.002)\end{array}$ & $\begin{array}{l}-0.0023 \\
(0.002)\end{array}$ & $\begin{array}{l}-0.0011 \\
(0.002)\end{array}$ & $\begin{array}{l}-0.0061 \\
(0.004)\end{array}$ & $\begin{array}{l}-0.0173^{* * *} \\
(0.005)\end{array}$ & $\begin{array}{l}-0.0018 \\
(0.001)\end{array}$ \\
\hline siness Sold or Closed & $\begin{array}{l}0.0051 \\
(0.005)\end{array}$ & $\begin{array}{l}0.0020 \\
(0.002)\end{array}$ & $\begin{array}{l}-0.0031 \\
(0.003)\end{array}$ & $\begin{array}{l}-0.0036 \\
(0.003)\end{array}$ & $\begin{array}{l}-0.0023 \\
(0.003)\end{array}$ & $\begin{array}{l}-0.0020 \\
(0.006)\end{array}$ & $\begin{array}{l}-0.0155 \\
(0.009)\end{array}$ & $\begin{array}{l}-0.0005 \\
(0.002)\end{array}$ \\
\hline
\end{tabular}

Notes: 8,327 individuals identified their reason for displacement as "job ended" or "laid off", and 2,304 identified their reason for displacement as "business sold or closed." Standard errors (in parentheses) are clustered at the individual level. ${ }^{*} p<.1 * * p<.05 * * * p<.01$. Estimates are weighted using MEPS person-level sampling weight. Displacement variables indicate involuntary displacement in the current round or a previous round. "Any Insurance," "Private Insurance," and "Public Insurance" represent current insurance status during the month of the interview, while "Ever Uninsured" indicates whether an individual was unemployed for at least one month during the current survey round. All utilization variables refer to the current survey round. All regressions include age and calendar year fixed effects and baseline health and mental health interacted with time trends. 